\title{
Electrochemical treatment of aluminium alloy 7075 in aqueous solutions of imidazolium phosphonate and phosphate ionic liquids and scratch resistance of the resultant materials
}

\author{
María-del-Mar Arrés, Ana-Eva Jiménez*, Joaquín Arias-Pardilla, Ginés Martínez-Nicolás, \\ María-Dolores Bermúdez
}

Grupo de Ciencia de Materiales e Ingeniería Metalúrgica, Departamento de Ingeniería de Materiales y Fabricación, Universidad Politécnica de Cartagena, Campus de la Muralla del Mar, 30202 Cartagena, Spain

\section{A R T I C L E I N F O}

\section{Keywords:}

Aluminium

Ionic liquids

Anodization

Chronoamperometry

Abrasion

\begin{abstract}
A B S T R A C T
The abilitiy of 1-ethyl-3-methylimidazolium ethylphosphonate ([ImPhosphonate]) and 1-ethyl-3-methylimidazolium diethylphosphate ([ImPhosphate]) ionic liquids (ILs) to interact with anodized Al7075 T6 aluminium alloy has been studied via electrochemical techniques under different applied potentials, inside and outside the passivation regions. SEM, EDX and XPS analysis have been used to study the composition of the surface coatings. The abrasion resistance after treatment with the ILs has been studied by scratch tests under progressive load, and compared with the performance of the unprotected material and the anodized alloy. While conventional anodization only improves the abrasion resistance of $\mathrm{Al} 7075$ in a 30\%, the maximum reduction of the penetration depth, $86 \%$ with respect to $\mathrm{Al} 7075$ and $79 \%$ with respect to the anodized alloy, is obtained for the material treated with [ImPhosphonate] at $1 \mathrm{~V}$, in the passivation region. Under these conditions, a phosphorus-containing alumina layer is formed. Applied voltages outside the passivation region for each IL activate the dissolution of the alumina layer and reduce abrasion resistance, not only with respect to the anodized material, but also with respect to the unprotected alloy.
\end{abstract}

\section{Introduction}

The use of light alloys such as aluminium, magnesium and titanium alloys has experienced a great expansion due to their good specific properties. However, the wear rate of light alloys tends to be higher than steel for the same tribological conditions. In particular, aluminium alloys present a lower abrasion resistance.

The anodization processes of aluminium have been extensively studied, and some authors have reported on the formation of anodic porous alumina using ionic liquid (ILs) as electrolytes [1-3]. In these studies, several neat imidazolium IL were used as electrolytes for anodization of pure aluminium applying electric potential values of up to $40 \mathrm{~V}$, finding that anion structure strongly affects the ability to form passive layers on the aluminium.

In the case of using fluorine-containing anions [1], a mixed film of $\mathrm{Al}_{2} \mathrm{O}_{3}$ and $\mathrm{AlF}_{3}$ was formed. The distribution and proportion of both compounds depends on the $\mathrm{pH}$ (pKa) of the electrolyte. Due to the small amount of water that is present in the IL as an impurity, there is a competition between oxide film-formation and film dissolution reactions during the anodic oxidation in the IL. In more acid solutions, at low potentials, anion oxidation reaction together with insertion of decomposed anion occurs, while at higher potential, dissolution of $\mathrm{Al}_{2} \mathrm{O}_{3}$ and reaction to form $\mathrm{AlF}_{3}$ occurs.

Salerno et al. [3] used imidazolium IL as additives (0.01-2 wt\%) of an oxalic solution to perform the anodization of pure aluminium, assessing that the addition of IL containing $\mathrm{BF}_{4}{ }^{-}$anion in a $1: 1 \mathrm{M}$ ratio with the oxalic acid increases the growth rate of anodic porous alumina.

For lithium battery applications, aluminium current collectors have shown less corrosion when IL electrolytes were used instead of traditional organic solvents [4-6]. After the application of a $4.2 \mathrm{~V}$ potential during $3 \mathrm{~h}$ in a solution of IL containing bis[(trifluoromethyl) sulfonyl] amide as the anion, a passivating film of Al-anion compounds was detected in the inner surface of the $\mathrm{Al}_{2} \mathrm{O}_{3} / \mathrm{AlF}_{3}$ surface layer.

Recently [7-9], the formation of surface films on magnesium alloy by treatment with ionic liquids (ILs) containing $\mathrm{P}$ has been studied. Although initial studies confirmed improvement in the corrosion resistance of magnesium alloys due to the formation of a passivating surface film when immersion in phosphonium IL, this surface film used to be heterogeneous and with defects [9]. Time, temperature, water content of IL and alloy microstructure play an important role in the

\footnotetext{
* Corresponding author.
} 
Table 1

Chemical structure of the ionic liquids.

Ionic liquid

1-ethyl-3-methylimidazolium diethylphosphate ([ImPhosphate])<smiles>CCOP(=O)(O)OCC</smiles>

Table 2

Chemical composition of Al7075 T6.

\begin{tabular}{llllllllll}
\hline Element & $\mathbf{S i}$ & $\mathrm{Fe}$ & $\mathrm{Cu}$ & $\mathbf{M n}$ & $\mathbf{M g}$ & $\mathrm{Zn}$ & $\mathrm{Ti}$ & $\mathrm{Cr}$ & $\mathrm{Al}$ \\
\hline Content (wt\%) & 0.3 & 0.45 & 1.5 & 0.17 & 2.25 & 5.5 & 0.06 & 0.18 & Balance \\
\hline
\end{tabular}

optimization of the passivation process of the magnesium alloys. In the case of using imidazolium IL with $\mathrm{P}$ in the anion $[7,8]$, it has been demonstrated an enhancement of the abrasion and wear resistance of the AZ31B alloy, attributed to the formation of a continuous adhered phosphorus-containing film, mainly composed of magnesium and aluminium phosphates.

Studies on the interaction between ILs and aluminium alloys are limited $[10,11]$. As far as we are aware, only one previous study [11] attempted the electrochemical etching of AA5083 aluminium alloys, instead of pure aluminium, with ILs. A 2-step anodic treatment with a phosphonium IL as the electrolyte was used, demonstrating the prevalence of an electrochemical etching process.

No previous studies on the effect of electrochemical treating with ILs on the tribological behaviour of aluminium alloys have been reported. The present study was recently presented at a conference [12].

\section{Experimental}

1-ethyl-3-methylimidazolium ethylphosphonate [ImPhosphonate] and 1-ethyl-3-methylimidazolium diethylphosphate [ImPhosphate] ionic liquids (Table 1) (purity >98\%) were commercially available from Solvionic (France) and used in $20 \mathrm{wt} \%$ aqueous solutions, with $\mathrm{pH}$ values of 6.6 for [ImPhosphonate] and 3.5 for [ImPhosphate].

Aluminium alloy 7075 T6 was purchased from Alu-Stock S.A. in the form of a $50 \mathrm{~mm}$ diameter rod, the elemental composition is listed in Table 2.

Test specimens were machined and cut to a shape of $40 \mathrm{~mm}$ diameter and $5 \mathrm{~mm}$ thickness. Before the electrochemical tests, aluminium samples were polished to a mean surface roughness (Ra) of 0.15 $\pm 0.03 \mu \mathrm{m}$, measured by a RT ALPA-SM contact profiler, then rinsed in deionized water and isopropanol, dried with air and put in a PTFE minicell [8].

Anodized Al7075 was obtained using a two electrode configuration for the anodic polarization (Fig. 1a), with a Pt wire as the counterpart. A constant voltage of $14 \mathrm{~V}$ was applied during $1 \mathrm{~h}$ using a solution of $18 \mathrm{wt} \%$ of $\mathrm{H}_{2} \mathrm{SO}_{4}$ in water as electrolyte. The voltage was applied with DC Power Supply SM10010 and data were recorded with a Keysight 34465 Digital Multimeter. The thickness of the $\mathrm{Al}_{2} \mathrm{O}_{3}$ layer was

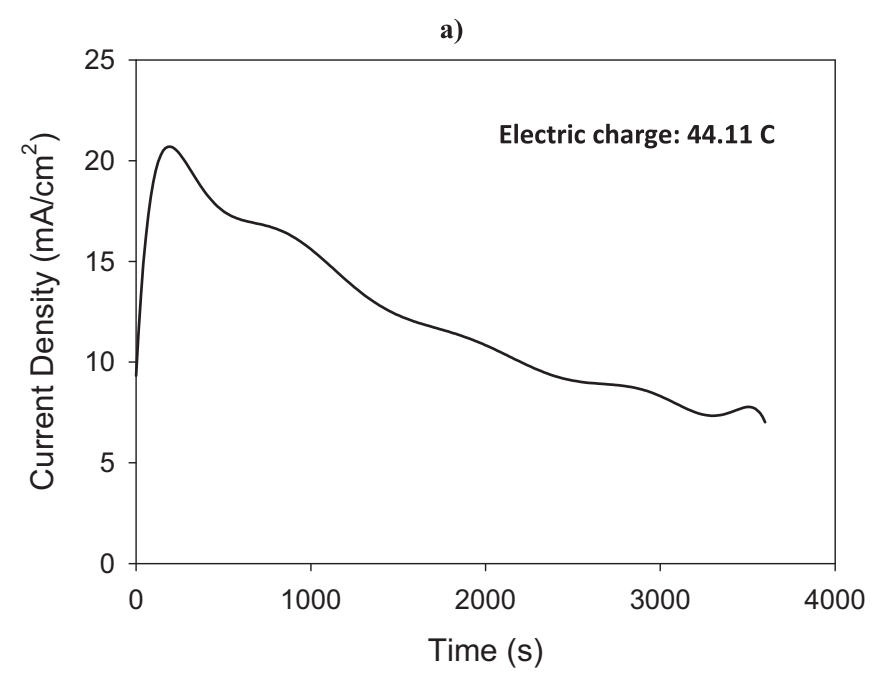

b)

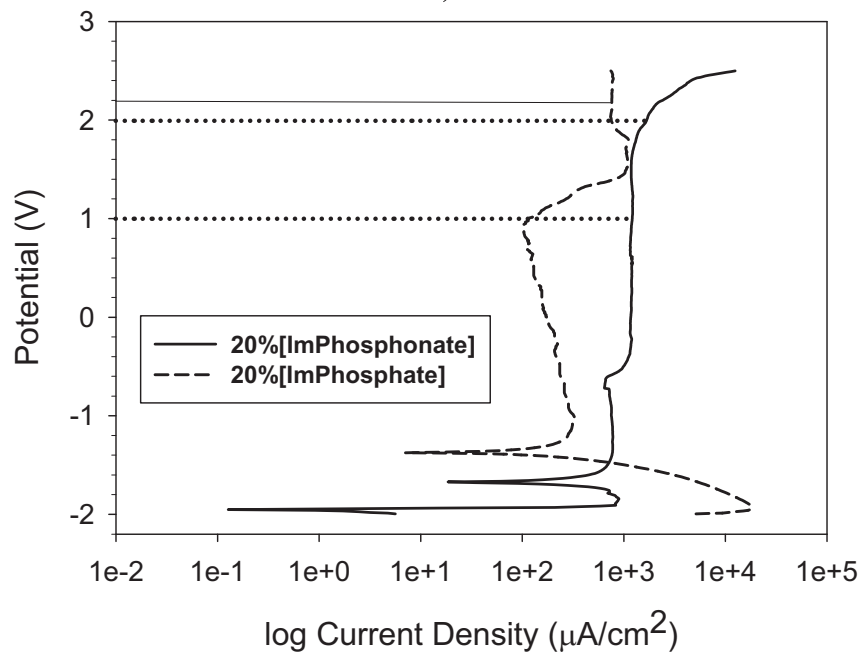

Fig. 1. a) Current density evolution for anodic polarization of $\mathrm{Al} 7075 \mathrm{~T} 6$ in $18 \mathrm{wt} \%$ $\mathrm{H}_{2} \mathrm{SO}_{4}$. Constant Potential of $14 \mathrm{~V}$; b) Potentiondynamic polarization tests for anodized Al7075 in 20 wt\% solutions of ILs showing the selected voltages.

measured by a coating thickness measuring system QNix 7500, with an average value of $30 \pm 5 \mu \mathrm{m}$.

Following anodization, the samples were treated by chronoamperometry method. Chronoamperometry tests were performed using a 


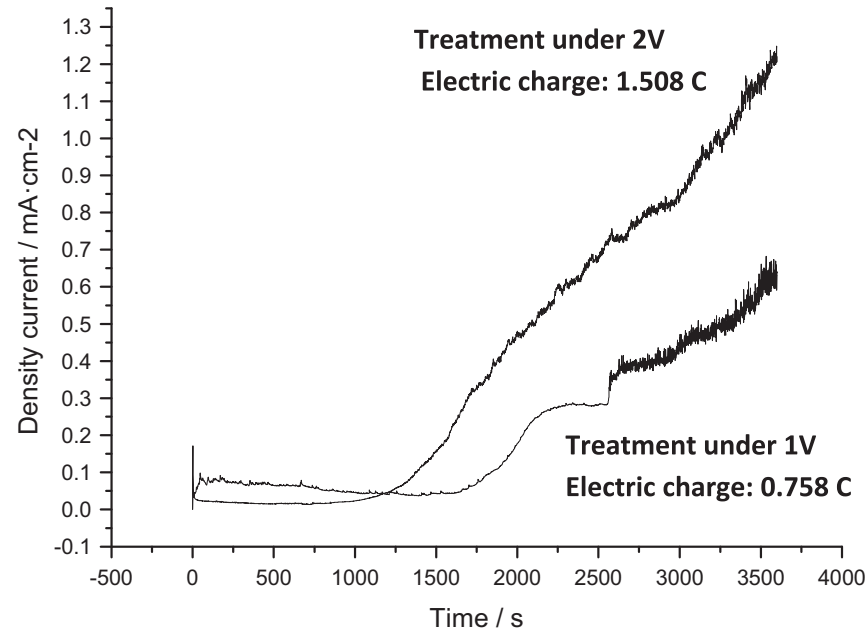

Fig. 2. Current density evolution over time during constant potential treatments in $20 \mathrm{wt} \%$ aqueous solution of [ImPhosphonate] under 1 or $2 \mathrm{~V}$.

three-electrode configuration, adding a calomel minielectrode (Standard Calomel Electrode, SCE) supplied by Bas Inc., as reference electrode, with a potential of $0.242 \mathrm{~V}$ vs Standard Hydrogen Electrode (SHE) at $25{ }^{\circ} \mathrm{C}$. The voltage was applied using a potentiostat Versastat $\mathrm{MC}$ and Versastudio software was used to collect the experimental data. The tests were conducted for $1 \mathrm{~h}$ at $1 \mathrm{~V}, 2 \mathrm{~V}$ and $4 \mathrm{~V}$ in the $20 \mathrm{wt} \%$ [ImPhosphonate] solution, and at $1 \mathrm{~V}$ and $2.2 \mathrm{~V}$ in the $20 \mathrm{wt} \%$ [ImPhosphate] solution. After each procedure, (anodization, or chronoamperometry) the samples were rinsed in deionized water and isopropanol, then dried with air.

The applied potentials were selected according to the potentiodynamic polarization tests in the IL water solutions (Fig. 1b).

Electrochemical impedance measurements (EIS) were performed in $3 \% \mathrm{NaCl}$ water solutions, using the Versastat $\mathrm{MC}$ potentiostat. The frequency ranged from $100 \mathrm{kHz}$ to $500 \mathrm{mHz}$ and the amplitude of the sinusoidal potential signal was $10 \mathrm{mV}$ with respect to OCP. The EIS tests were always conducted from high frequency to low frequency, and ZSimpWin 3.21 software was used for the data fitting of impedance spectra.

a)

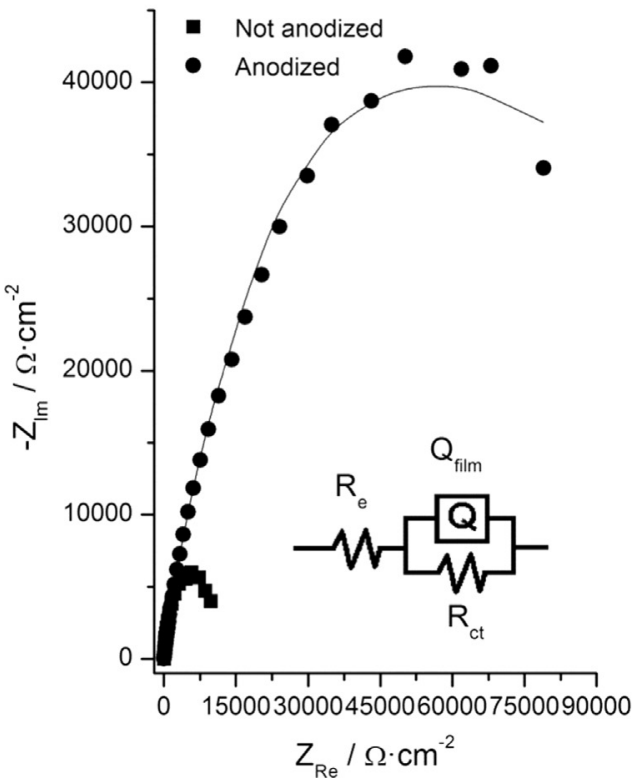

Abrasion resistance was measured with a Scratch tester MTR3/5050/NI (Microtest, Spain), under progressively increasing load applied by a diamond-tip indenter ( $200 \mu \mathrm{m}$ diameter and $120^{\circ}$ cone angle), was used. Load varying from 0.1 to $30 \mathrm{~N}$ at $10 \mathrm{Nmm}^{-1}$, length of the scar of $3 \mathrm{~mm}$. In scratch tests, a hard asperity of diamond is used against the sample surface with a controlled penetration load. The penetration depth of the diamond tip into the surface layer can be used as a measure of the abrasion resistance of the sample. The application of a progressively incrementing load as the tip moves along the surface make it possible to establish the value of the critical load for the failure of coatings and surface layers. For the determination of the penetration depth, the mean value corresponding to the maximum depth of 20 longitudinal profiles of the central area of the scratch was determined. All abrasion tests were repeated at least three times. Average surface roughness (Sa) was measured outside the scars in a $0.4 \times 0.8 \mathrm{~mm}$ area. The surface roughness Sa is a height parameter defined by standard ISO 25178-2:2012 as"the arithmetic mean value of the absolute of the ordinate values within a definition area". The 2D and 3D surface profiles, Sa, and Pd were recorded using a Talysurf CLI optical profiler and TalyMap Gold Software (Taylor Hobson Ltd).

SEM micrographs were obtained with a Hitachi S-3500N. XPS analysis was obtained with a ESCA 5701 from Physical Electronics (PHI), with $\pm 0.1 \mathrm{eV}$ precision for binding energy values. The binding energies were referenced to the $\mathrm{C} 1 \mathrm{~s}$ peak $(285.0 \mathrm{eV})$ used as internal standard. To resolve peaks with very close binding energy values, after background subtraction, we fitted the spectra using CasaXPS software (v.2.3.15, Casa Software, Ltd., Wilmslow, Cheshire, U.K).

\section{Results and discussion}

\subsection{Electrochemical treatments}

Anodized Al7075 shows a passivation region for both IL solutions (Fig. 1b). Therefore, potentials inside these passivation regions ( $1 \mathrm{~V}$ for [ImPhosphonate] and 2,2 V for [ImPhosphate]), and outside it ( $2 \mathrm{~V}$ and $4 \mathrm{~V}$ for [ImPhosphonate], and $1 \mathrm{~V}$ for [ImPhosphate]) were selected.

Fig. 2 shows current density evolution over time during constant potential treatment in $20 \mathrm{wt} \%$ aqueous solution of [ImPhosphonate], at 1 or $2 \mathrm{~V}$. Low current values are observed during induction time. In the

b)

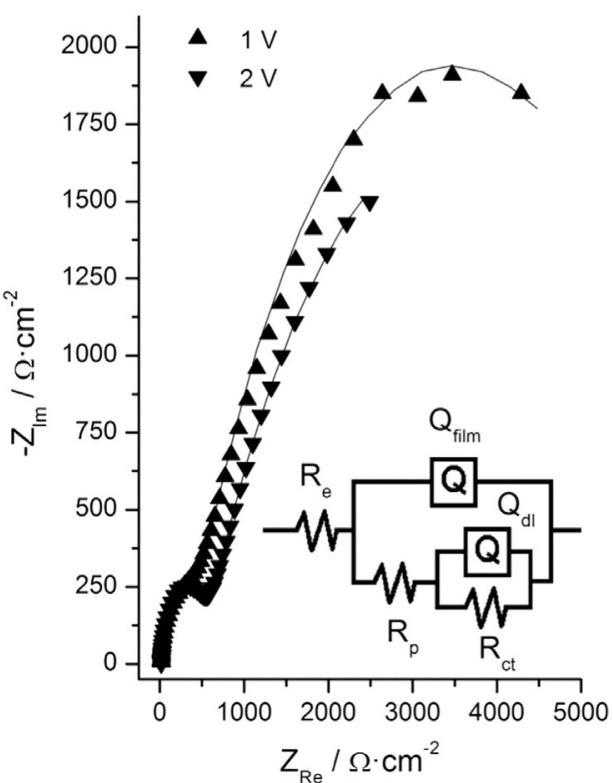

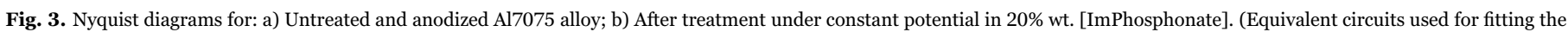
curves are included). 
Table 3

Values of the equivalent circuits obtained by fitting the experimental data.

\begin{tabular}{|c|c|c|c|c|c|c|c|c|c|}
\hline Electrode condition & $\operatorname{Re}(\Omega)$ & $Q_{\text {film }}\left(S \cdot \mathbf{s}^{\mathbf{n}}\right)$ & $\mathbf{n}$ & $\mathrm{C}_{\mathrm{film}}(\mathrm{pF})$ & $\operatorname{Rp}(\Omega)$ & Qdl $\left(S \cdot \mathbf{s}^{\mathbf{n}}\right)$ & $\mathbf{n}$ & Cdl (pF) & Ret $(\Omega)$ \\
\hline Al7075 T6 & 20.4 & $7.4 \times 10^{-6}$ & 0.94 & 2.8 & - & - & - & - & $1.11 \cdot 10^{4}$ \\
\hline Anodized Al7075 T6 & 22.1 & $2.0 \times 10^{-6}$ & 0.78 & 0.03 & - & - & - & - & $1.13 \cdot 10^{5}$ \\
\hline Anodizing $+[$ ImPhosphonate $]$ (1 V) & 16.0 & $1.8 \times 10^{-6}$ & 0.90 & 0.18 & 505 & $4.41 \times 10^{-5}$ & 0.70 & 0.08 & $6.1 \cdot 10^{3}$ \\
\hline Anodizing $+[$ ImPhosphonate $]$ (2 V) & 14.1 & $2.1 \times 10^{-6}$ & 0.92 & 0.38 & 538 & $1.96 \times 10^{-4}$ & 0.64 & 0.09 & $6.2 \cdot 10^{3}$ \\
\hline
\end{tabular}

a)

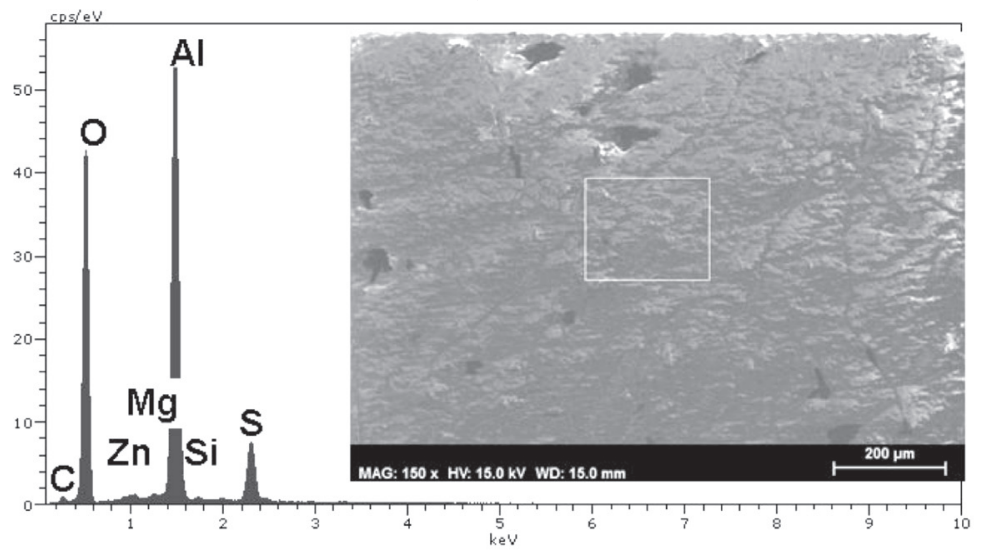

b)

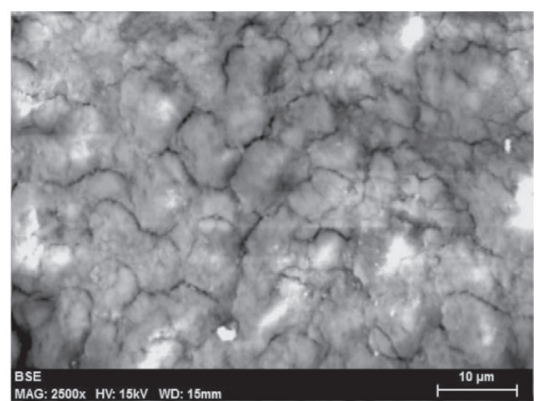

c)

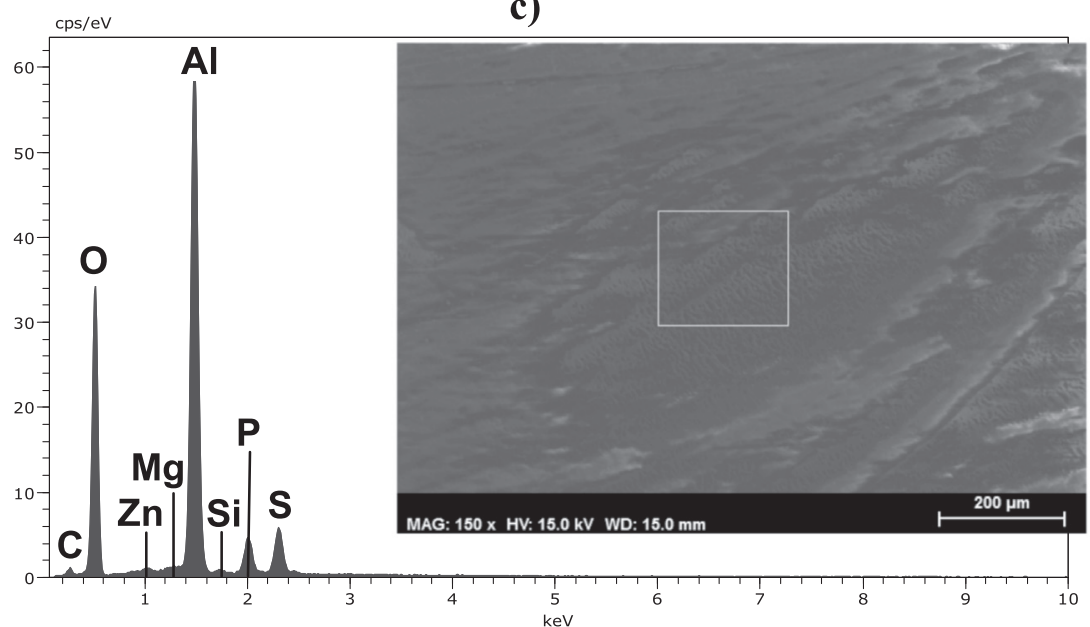

d)

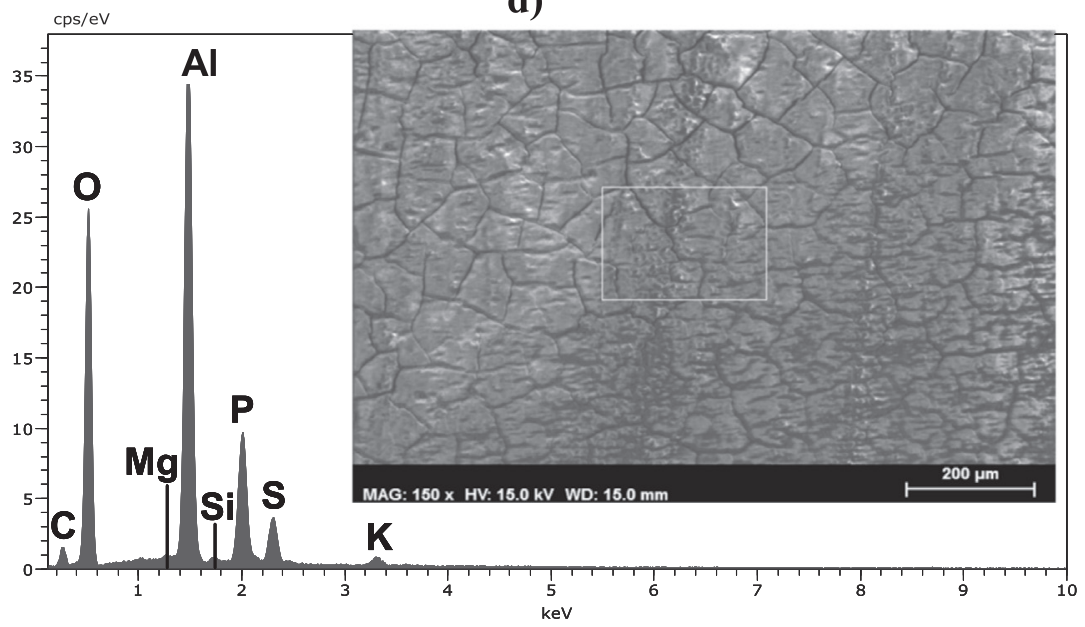

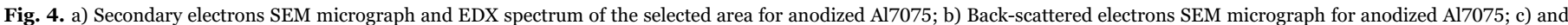
d) Secondary electrons SEM micrograph and EDX spectrum of the selected area for anodized Al7075 after treatment with [ImPhosphonate] at $1 \mathrm{~V}$ and $4 \mathrm{~V}$ respectively. 
a)

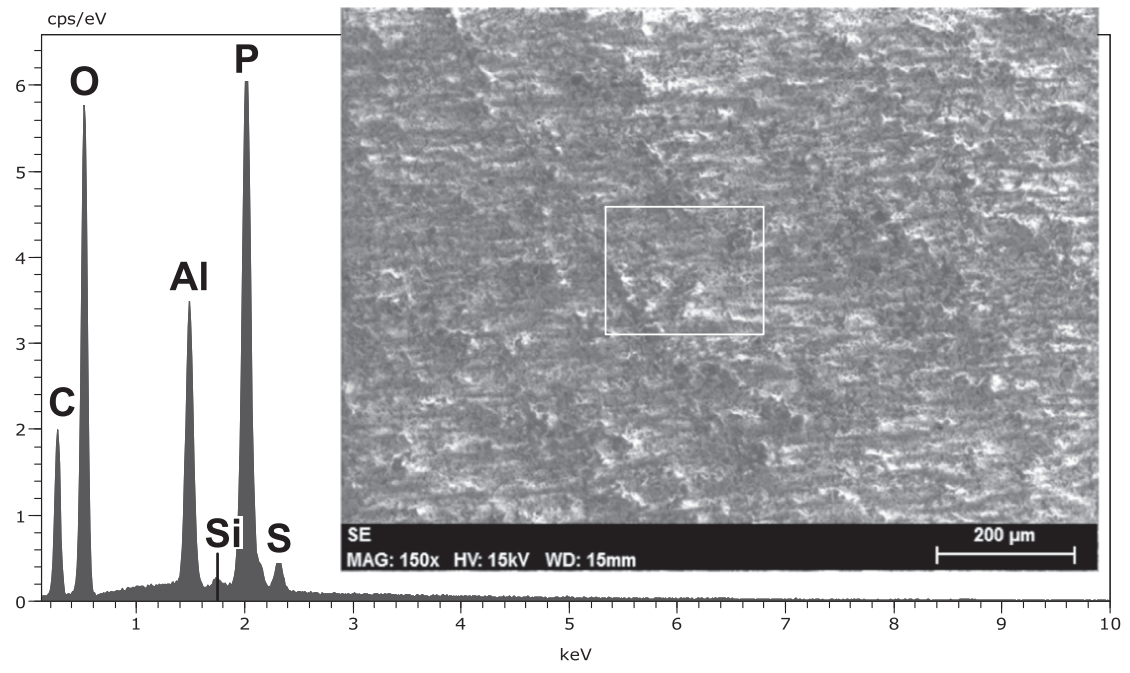

b)

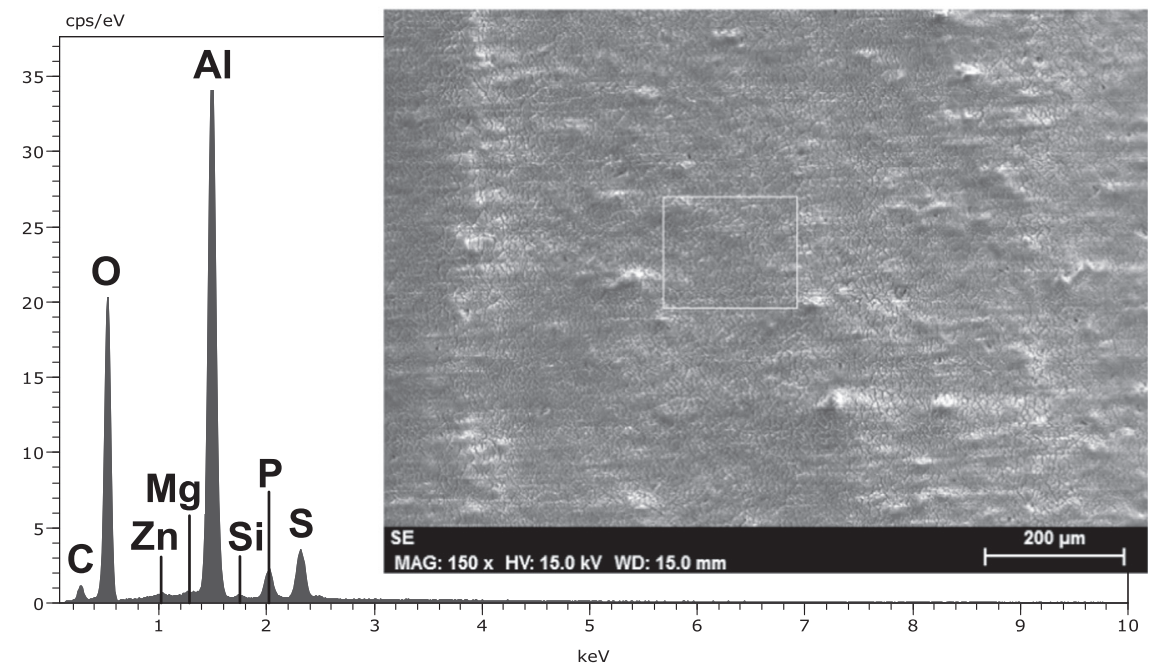

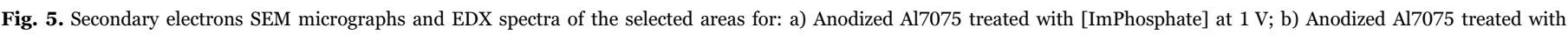
[ImPhosphate] at $2.2 \mathrm{~V}$.

Table 4

XPS analysis of Al7075 T6 after anodizing and after treatment with [ImPhosphonate] (1 V and $4 \mathrm{~V}$ ) and [ImPhosphate] (2.2 V).

\begin{tabular}{|c|c|c|c|c|c|c|c|c|}
\hline \multirow[t]{2}{*}{ Element } & \multicolumn{2}{|c|}{ Anodized Al 7075 T6 } & \multicolumn{2}{|c|}{$\begin{array}{l}\text { Anodized Al } 7075 \\
\text { T6+[ImPhosphonate] (1 V) }\end{array}$} & \multicolumn{2}{|c|}{$\begin{array}{l}\text { Anodized Al } 7075 \\
\text { T6+[ImPhosphonate] }(4 \mathrm{~V})\end{array}$} & \multicolumn{2}{|c|}{$\begin{array}{l}\text { Anodized Al } 7075 \\
\text { T6+[ImPhosphate] (2.2 V) }\end{array}$} \\
\hline & $\begin{array}{l}\mathrm{eV} \text { (atomic } \\
\%)\end{array}$ & $\begin{array}{l}\text { Deconvolution } \mathrm{eV} \\
\text { (relative \%) }\end{array}$ & $\begin{array}{l}\mathrm{eV} \text { (atomic } \\
\%)\end{array}$ & $\begin{array}{l}\text { Deconvolution eV } \\
\text { (relative \%) }\end{array}$ & $\begin{array}{l}\mathrm{eV} \text { (atomic } \\
\%)\end{array}$ & $\begin{array}{l}\text { Deconvolution eV } \\
\text { (relative \%) }\end{array}$ & $\begin{array}{l}\mathrm{eV} \text { (atomic } \\
\%)\end{array}$ & $\begin{array}{l}\text { Deconvolution eV } \\
\text { (relative \%) }\end{array}$ \\
\hline O 1 s & $\begin{array}{l}532.2 \\
(51.8)\end{array}$ & - & $532.1(54.4)$ & $\begin{array}{l}531.3(13.5) \\
532.3(40.9)\end{array}$ & $532.4(52.0)$ & $\begin{array}{l}531.5(13.5) \\
532.5(38.5)\end{array}$ & $532.2(58.9)$ & $\begin{array}{l}531.2(18.0) \\
532.3(40.9)\end{array}$ \\
\hline Al 2p & $74.6(18.8)$ & $74.5(12.5)$ & $74.7(22.3)$ & $74.6(14.9)$ & $74.9(16.9)$ & $\begin{array}{l}74.6(9.0) \\
75.3(4.5)\end{array}$ & 74.4 (21.9) & $74.4(14.6)$ \\
\hline & & $75.2(6.3)$ & & $75.2(7.4)$ & & $\begin{array}{l}75.4(2.3) \\
76.1(1.1)\end{array}$ & & $75.1(7.3)$ \\
\hline $\mathbf{S} \mathbf{2 p}$ & $169.5(4.0)$ & $\begin{array}{l}169.3(2.7) \\
170.5(1.3)\end{array}$ & $169.7(2.6)$ & $\begin{array}{l}169.3(1.7) \\
170.7(0.9)\end{array}$ & 169.7 (1.5) & $\begin{array}{l}169.5(1.0) \\
170.5(0.5)\end{array}$ & $169.7(2.7)$ & $\begin{array}{l}169.2(1.8) \\
170.6(0.9)\end{array}$ \\
\hline $\mathbf{P} \mathbf{2 p}$ & - & - & $134.5(5.2)$ & $\begin{array}{l}134.0(3.5) \\
134.9(1.7)\end{array}$ & 134.4 (9.7) & $\begin{array}{l}134.1(6.5) \\
135.0(3.2)\end{array}$ & $134.3(2.7)$ & $\begin{array}{l}134.1(1.8) \\
135.0(0.9)\end{array}$ \\
\hline
\end{tabular}

case of $1 \mathrm{~V}$, the induction time is near $1750 \mathrm{~s}$ and decreases to $1250 \mathrm{~s}$ under $2 \mathrm{~V}$. An almost linear current increase is then observed under $2 \mathrm{~V}$, whereas a constant value of $0.28 \mathrm{~mA} \mathrm{~cm}^{-2}$ is reached using $1 \mathrm{~V}$, before further current density increases. Electrical charges used during the treatment have been obtained by integration, and are 0.758 and $1.508 \mathrm{C}$, respectively. 

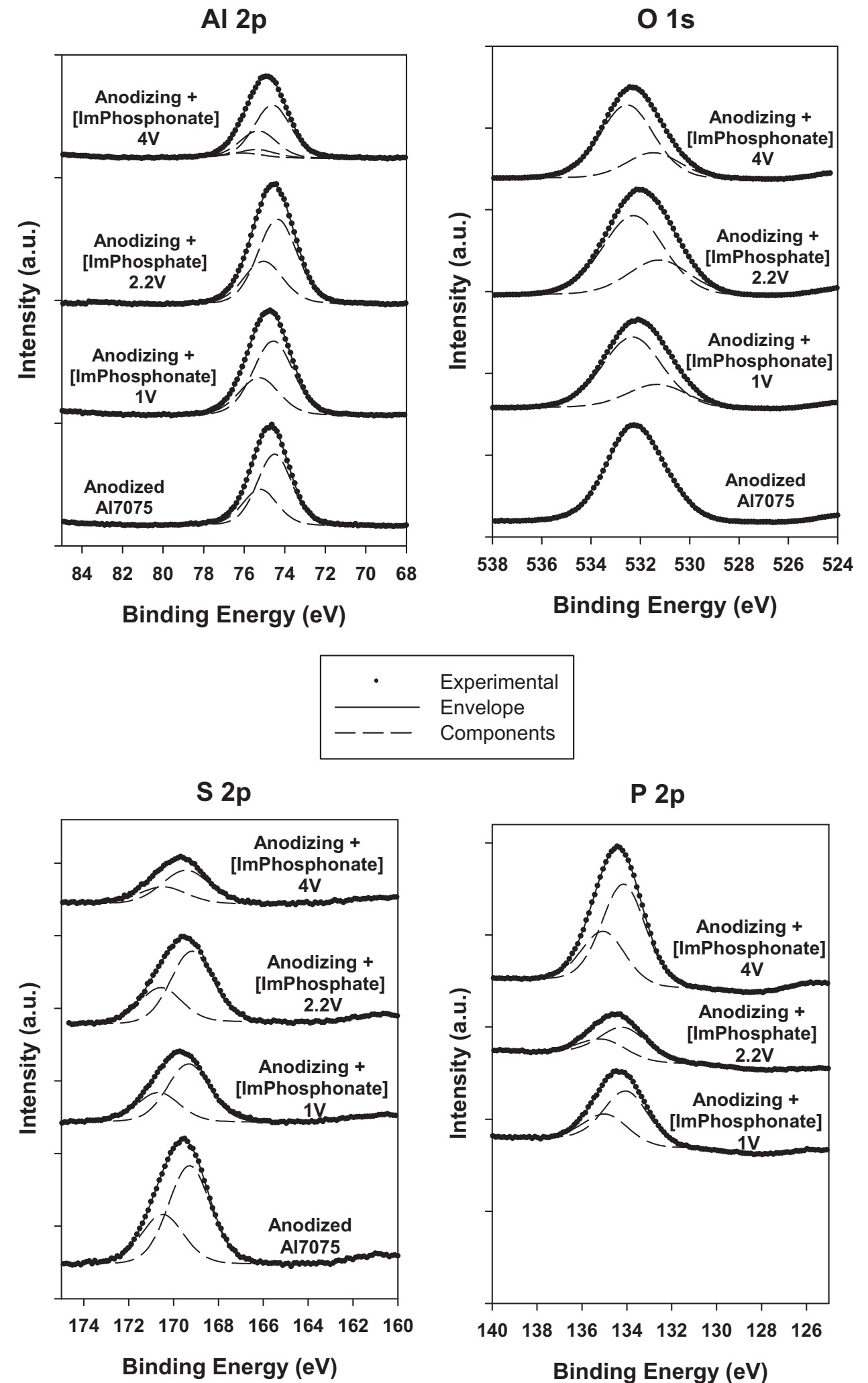

\section{Experimental \\ Envelope \\ Components}

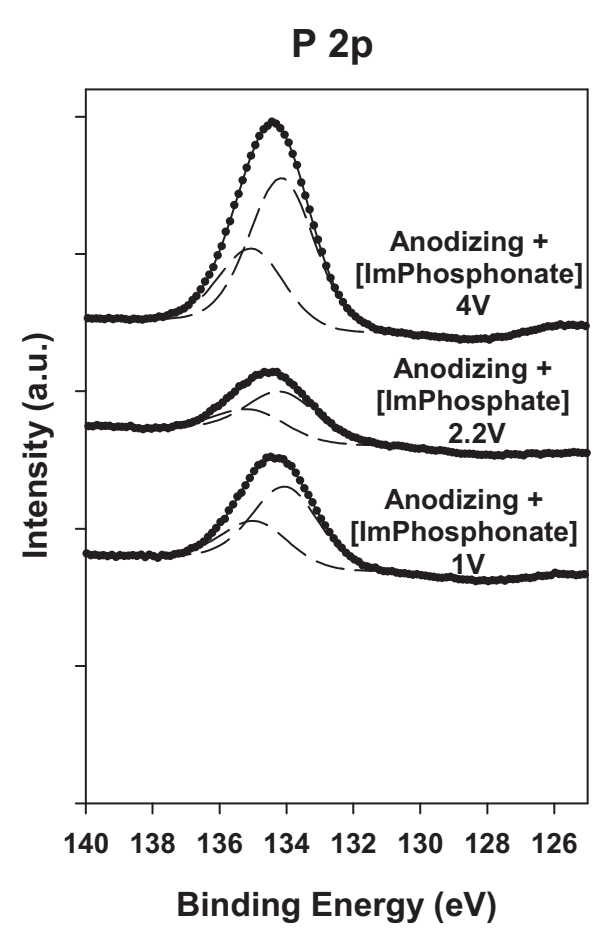

Fig. 6. Al2p, O1s, S2p and P2p XPS spectra for anodized Al7075 and for anodized Al7075 after tratment with [ImPhosphonate] (1 V and 4 V) and with [ImPhosphate] (2.2 V).

\subsection{Electrochemical impedance measurements (EIS)}

The effect on the anodized layer of the constant electric potential treatment in $20 \%$ wt of [ImPhosphonate] was studied by electochemical impedance measurements using $3 \% \mathrm{NaCl}$ solution as electrolyte. The impedance data are displayed in Fig. 3, in the form of Nyquist plots. An impedance module increase is clearly observed after the anodization treatment (Fig. 3a).

Table 3 shows impedance parameters obtained by ZSimpWin 3.21 software using equivalent circuits shown in Fig. 3. Electrode before and after anodization treatment is represented by a series of solution resistance (Re) and high-impedance insulating film with resistance 


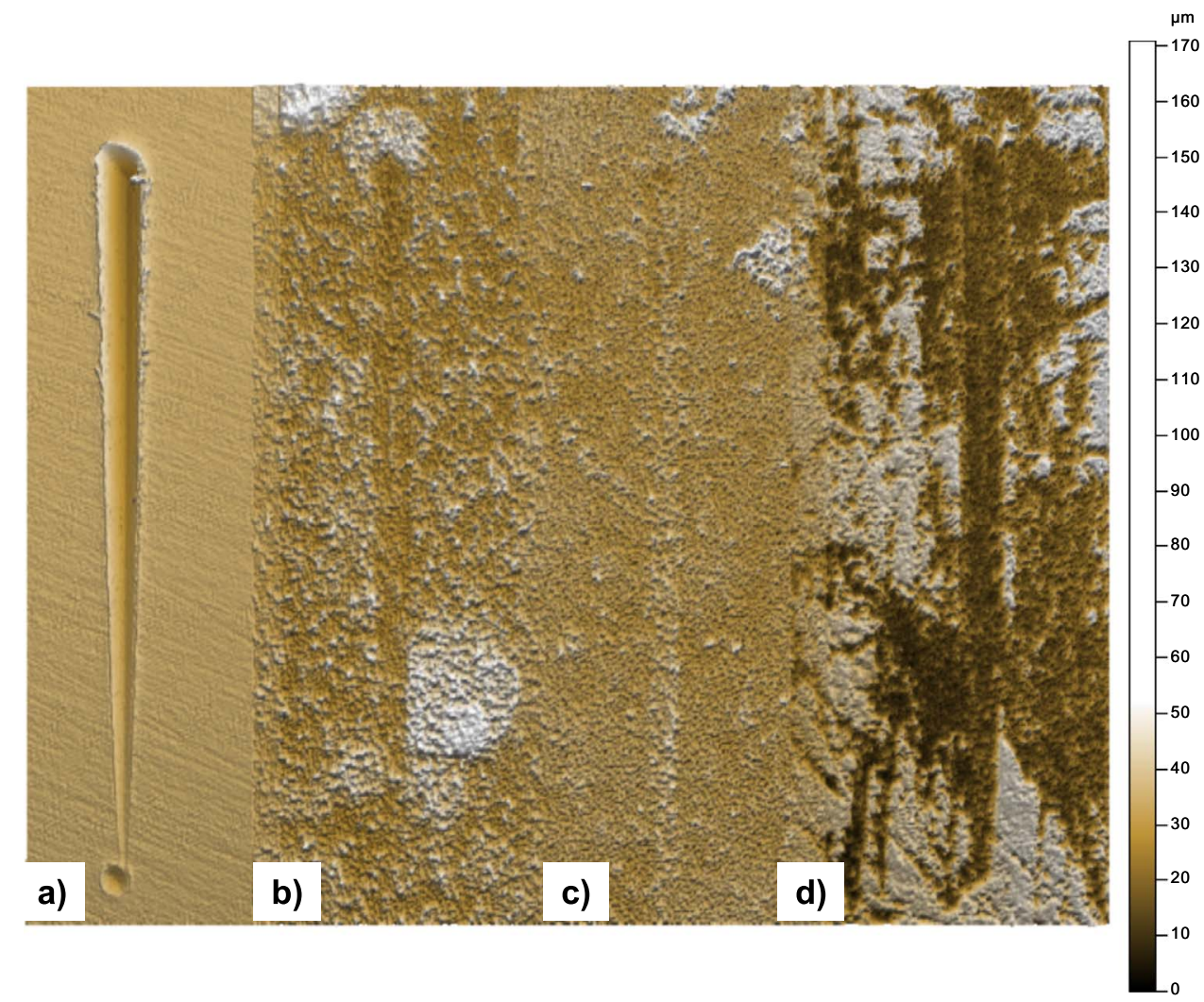

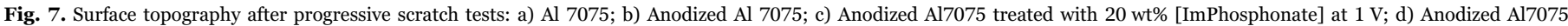
treated with $20 \mathrm{wt} \%$ [ImPhosphonate] at $2 \mathrm{~V}$.

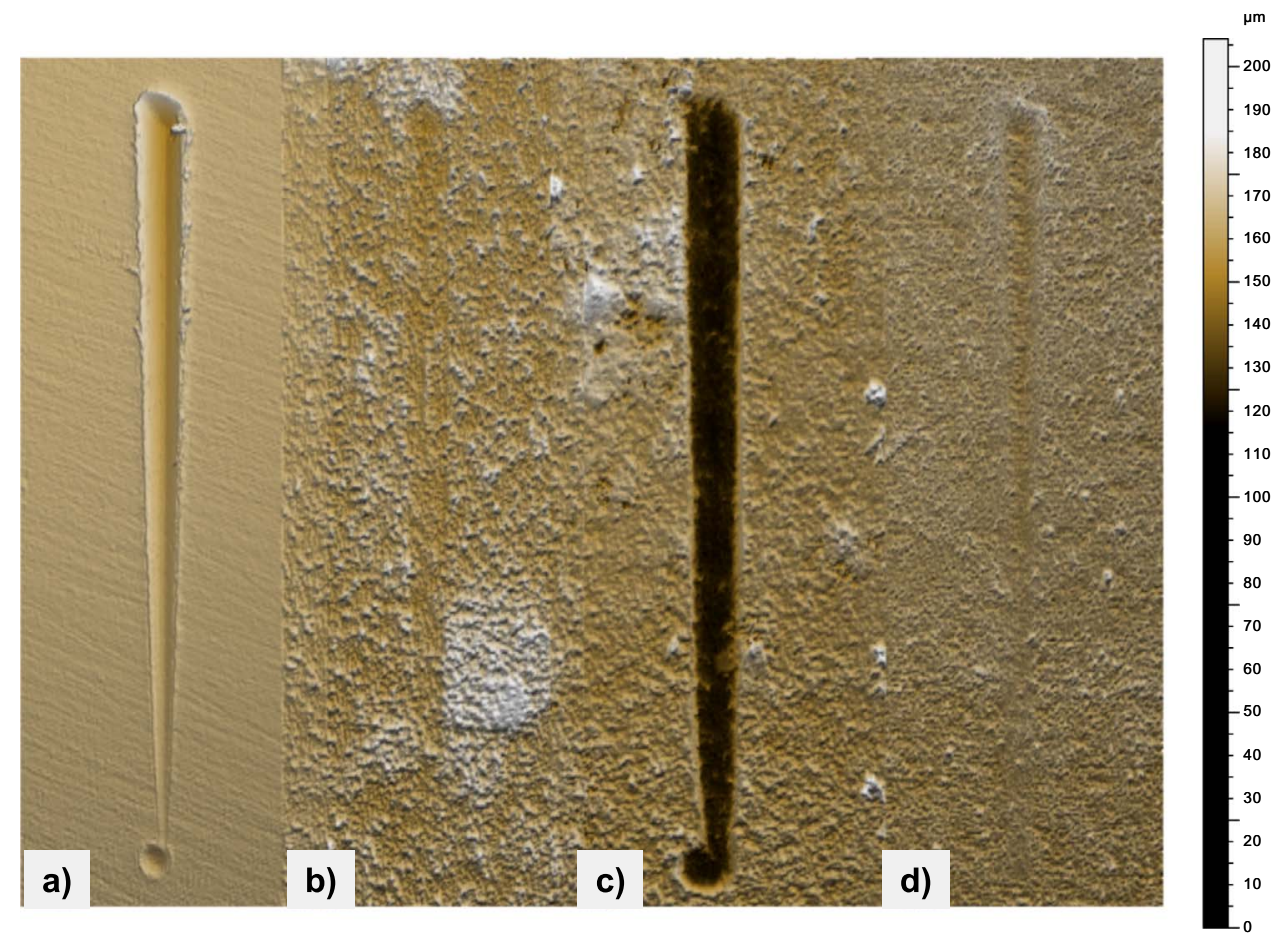

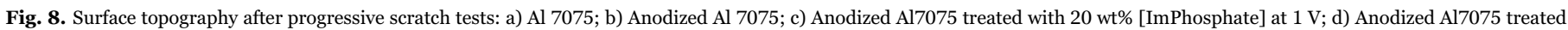
with $20 \mathrm{wt} \%$ [ImPhosphate] at $2.2 \mathrm{~V}$.

Rct and constant phase element (CPE) Qfilm in parallel. As CPE is used in the fitting, "true" capacitance can be obtained from Eq. (1):

$C=\left(Q \cdot R^{n-1}\right)^{1 / n}$ where $\mathrm{C}$ is the capacitance, $\mathrm{Q}$ is the constant phase element and $\mathrm{n}=1$ for an ideal capacitor.

After anodization, electrode capacitance $\left(\mathrm{C}_{\text {film }}\right)$ is reduced by two orders of magnitude and Rct is increased by one order of magnitude, as 


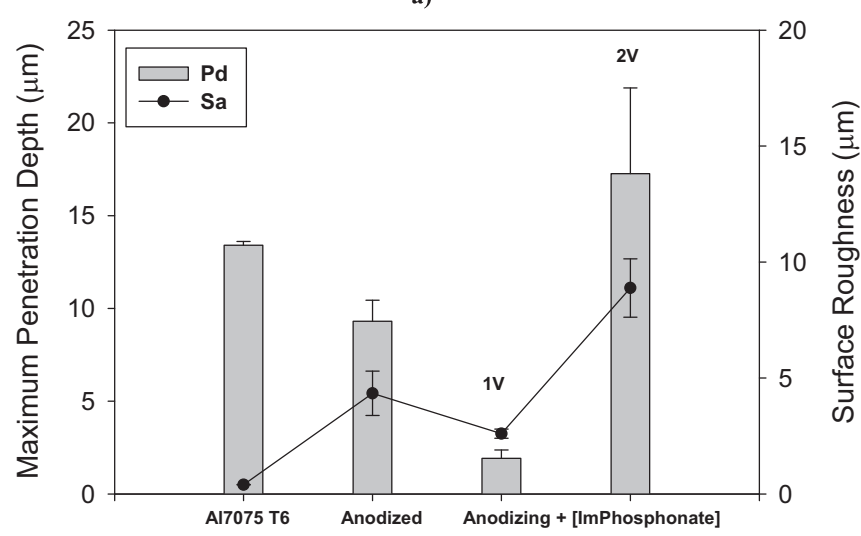

b)

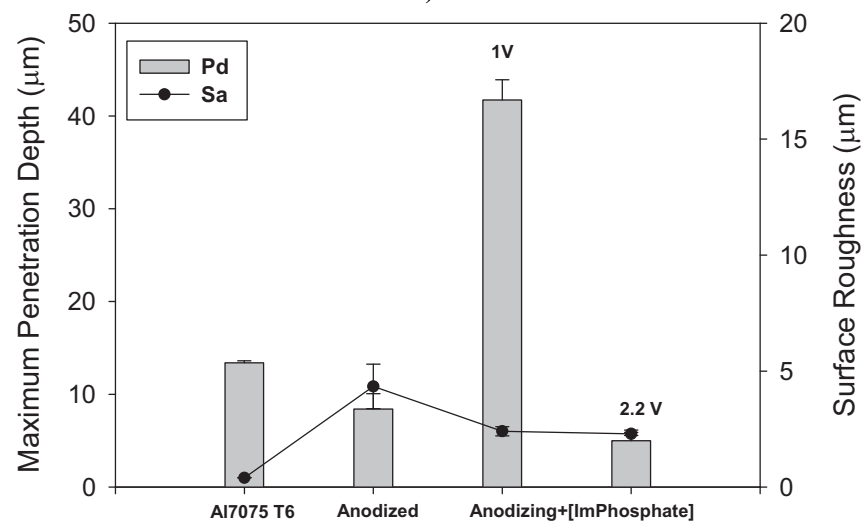

Fig. 9. Surface roughness (Sa) values and maximum penetration depth (Pd) for Al7075, for anodized Al7075, and for anodized Al7075 after treatment with. a) [ImPhosphonate] at $1 \mathrm{~V}$ and $2 \mathrm{~V}$, and with b) [ImPhosphate] at $1 \mathrm{~V}$ and $2.2 \mathrm{~V}$ (notice the different penetration depth scale).

a result of the generation of a thicker alumina film.

When constant potential treatment is applied, a more complex behaviour is observed. Impedance module decreases to lower values to that obtained before anodization. In this case, a different equivalent circuit (Fig. 3b) has to be used to fit the experimental data. This circuit takes into account new elements, such as pore resistance of the film (Rp) and capacitance of a new interface between film and electrode (Qdl). As can be observed in Table 3, the values of charge transfer resistance are lower after applying constant potential and the capacitance of the film increases from the anodized test.

The higher the applied potential, the higher the capacities (both Cfilm and Cdl) obtained. In the case of Rct, almost the same value is obtained. In spite of the relatively low charge applied during constant potential treatment, a pronounced effect in the anodized film is observed.

\subsection{Surface analysis}

Figs. 4 and 5 show SEM micrographs and EDX spectra of anodized Al7075 (Fig. 4a and b) and anodized aluminium after treatment with the [ImPhosphonate] (Fig. 4c and d) and [ImPhosphate] (Fig. 5) ILs under different potentials. The non-conductive nature of the anodized surface layer produce poor quality secondary electron images (Fig. 4a). Grain microstructure of the anodizing coating can be seen in the backscattered electron micrograph (Fig. 4b). After treatment at $1 \mathrm{~V}$ in the [ImPhosphonate] solution (Fig. 4c), the secondary electron image shows a more uniform surface and the EDX spectrum shows a new phosphorus peak (2.6 at\%) from the phosphonate anion, together with a relative decrease of the intensity of the oxygen peak (55.9 at\%) with respect to anodized Al7075 (63.2 at\%) (Fig. 4a). A further increase of the phosphorus peak (7.1 at\%) is observed for the layer obtained under $4 \mathrm{~V}$, where grain boundaries are clearly seen in the secondary electron micrograph (Fig. 4d).

Treatment with [ImPhosphate] (Fig. 5a and b) show rough surfaces. At $1 \mathrm{~V}$, the composition of the coating has clearly changed, as revealed by the increase of the intensity of the phosphorus peak (12.0 at\%), and the reduction of the intensity of the aluminium peak (5.5 at\%). This change in the $\mathrm{Al}$ content could be tentatively attributed to a decrease in the alumina content, due to partial dissolution of the layer in the acid $\mathrm{pH}$ (3.5) of the [ImPhosphate] aqueous solution. The EDX spectrum obtained for [ImPhosphate] at $2.2 \mathrm{~V}$ (Fig. $5 \mathrm{~b}$ ) is very similar to that described for [ImPhosphonate] at $1 \mathrm{~V}$ (Fig. 4c).

Table 4 and Fig. 6 show XPS surface analysis results for anodized Al7075 T6 before and after treatment with the imidazolium phosphonate IL, [ImPhosphonate], at 1 and $4 \mathrm{~V}$. The Al2p, S2p and P2p peaks have been deconvoluted to show $2 \mathrm{p}_{3 / 2}$ and $2 \mathrm{p}_{1 / 2}$ binding energies.

Anodized Al7075 shows only one O1s peak, at $532.2 \mathrm{eV}$, which together with the $\mathrm{Al} 2 \mathrm{p}$ peak at $74.6 \mathrm{eV}$, could be assigned to aluminium oxide [13].

After treatment with [ImPhosphonate] at $1 \mathrm{~V}$, the atomic percentages of $\mathrm{Al} 2 \mathrm{p}$ and $\mathrm{O} 1 \mathrm{~s}$ increase, while $\mathrm{S} 2 \mathrm{p}$, from the sulfate anion, decreases. The $\mathrm{O} 1 \mathrm{~s}$ spectrum is now formed by two peaks, the most abundant one, at $532.3 \mathrm{eV}$, is assignable to aluminium oxide, while the minor O1s peak at $531.3 \mathrm{eV}$, and the new P2p peak at $134.7 \mathrm{eV}$ could be assignable to the presence of phosphates [13].

Treatment of anodized Al7075 with the imidazolium phosphate IL, [ImPhosphate], at $2.2 \mathrm{eV}$ results in binding energies very similar to those obtained for the phosphonate species at $1 \mathrm{~V}$.

As it will be shown later, these results support the hypothesis that the modification of the anodized layer by the IL anions is responsible for the enhancement of the abrasion resistance of Al7075 T6.

When anodized Al7075 was treated with [ImPhosphonate] at $4 \mathrm{~V}$, outside the passivation region (Fig. 1b), the aluminium percentage decreases, while the phosphorus atomic percentage increases, with respect to the spectra obtained after treatment at $1 \mathrm{~V}$. The $\mathrm{Al} 2 \mathrm{p}$ spectrum can now be deconvoluted in two doublet peaks, with a new doublet at higher binding energies, with respect to anodized Al7075 treated with [ImPhosphonate] at $1 \mathrm{~V}$. These results would be in agreement with partial dissolution of alumina and formation of aluminium phosphate.

\subsection{Abrasion tests}

Figs. 7 and 8 show abrasion marks, comparing Al7075 and anodized Al7075 with the anodized material treated with phosphonate (Fig. 7) or phosphate (Fig. 8) ILs at different voltages. The corresponding values of surface roughness for each surface finish and the maximum penetration depth values (corresponding to the maximum applied load at the end of the scars) are shown in Fig. 9.

After anodization, treatment with IL within the passivation region reduces surface roughness and increases abrasion resistance. Taking the anodized material as a reference, treatment under $1 \mathrm{~V}$ in the [ImPhosphonate] solution (Fig. 9a) reduces the maximum penetration depth by $79 \%$, while the treatment with the [ImPhosphate] solution (Fig. 9b) under $2.2 \mathrm{~V}$ gives a $46 \%$ reduction. The materials with the highest abrasion resistance (Anodizing + [ImPhosphonate] $(1 \mathrm{~V})$ and Anodizing $+[$ ImPhosphate $](2.2 \mathrm{~V})$ ) are those which present lower roughness values.

In contrast, applying voltages outside the passivation region reduces the abrasion resistance not only with respect to the anodized material, but also with respect to the untreated Al7075 alloy, for both ILs, as can be observed in Figs. $7 \mathrm{~d}$ and $8 \mathrm{c}$.

These results have been confirmed by the cross section profiles of the abrasion scars (Fig. 10). The more ductile and polished Al7075 shows a progressively increasing penetration depth as the applied load 


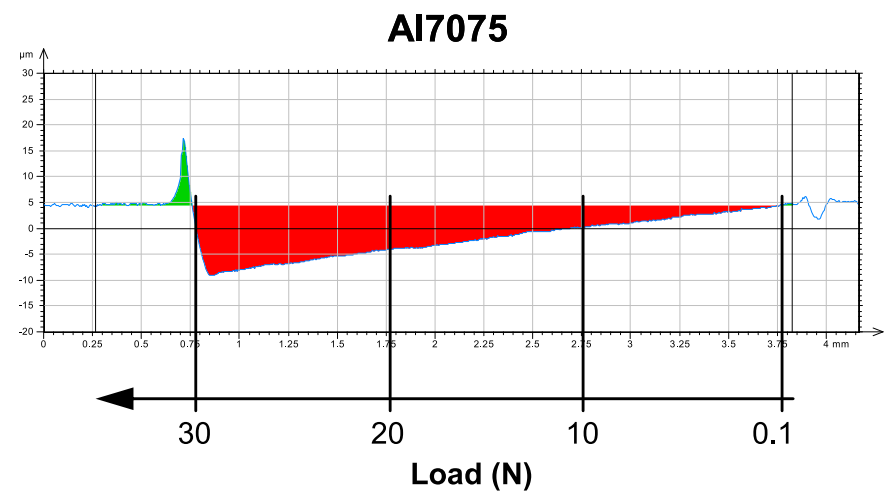

Anodized Al7075+[ImPhosphonate] (1V)

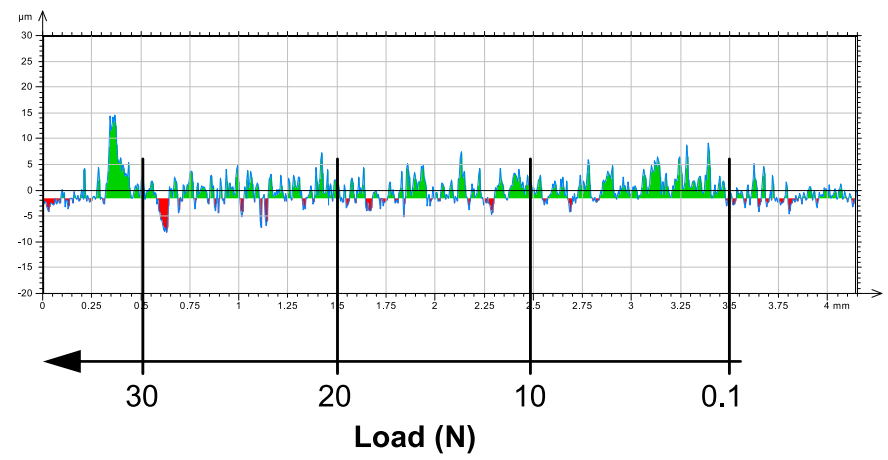

Anodized Al $7075+[$ ImPhosphate $]$

(1V)

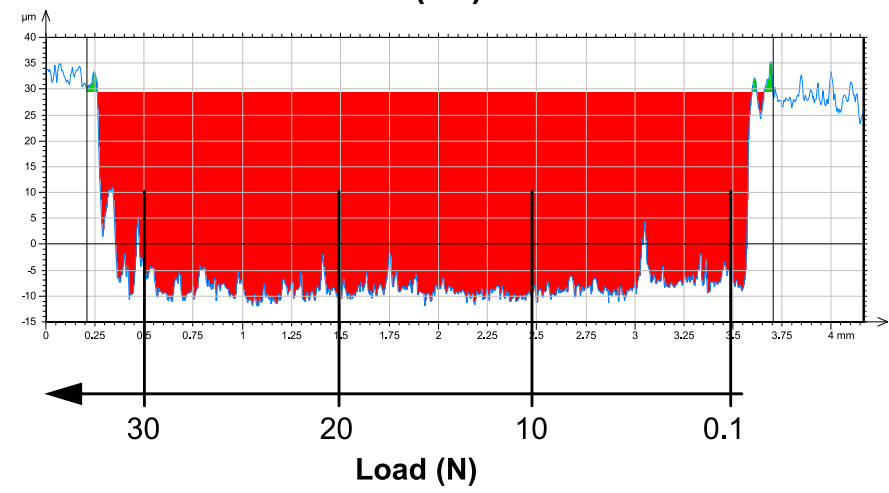

Anodized Al7075

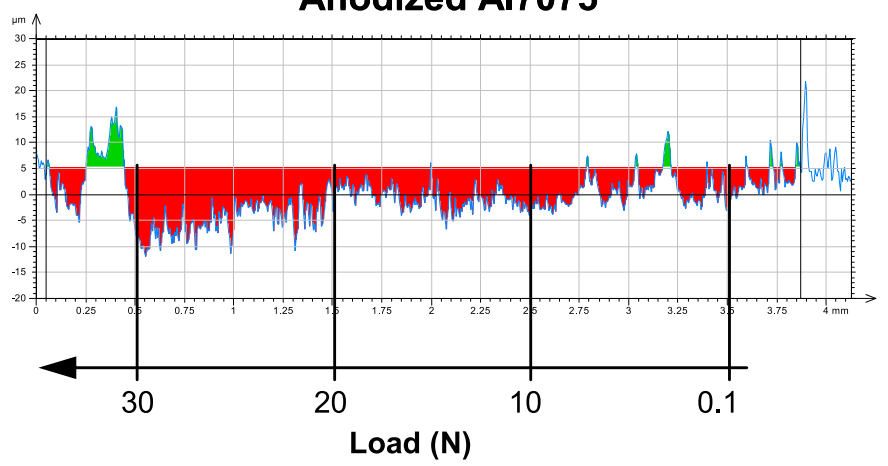

Anodized Al7075+[ImPhosphonate]

(2V)

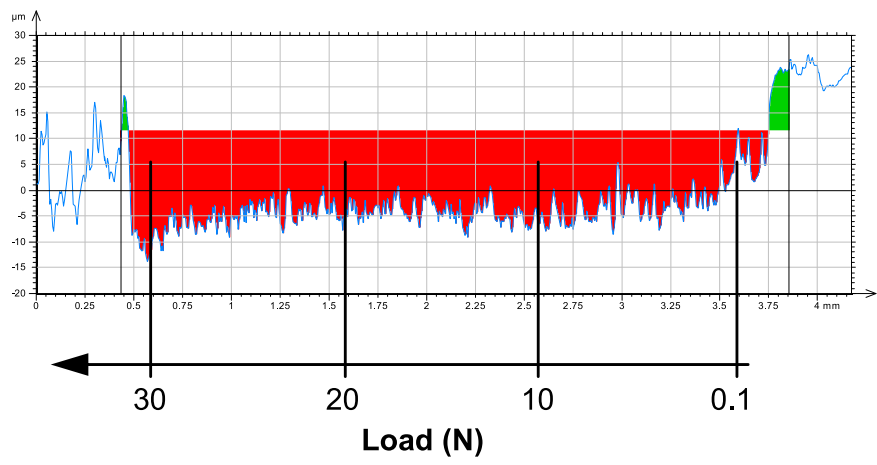

Anodized Al $7075+$ [ImPhosphate]

(2.2V)

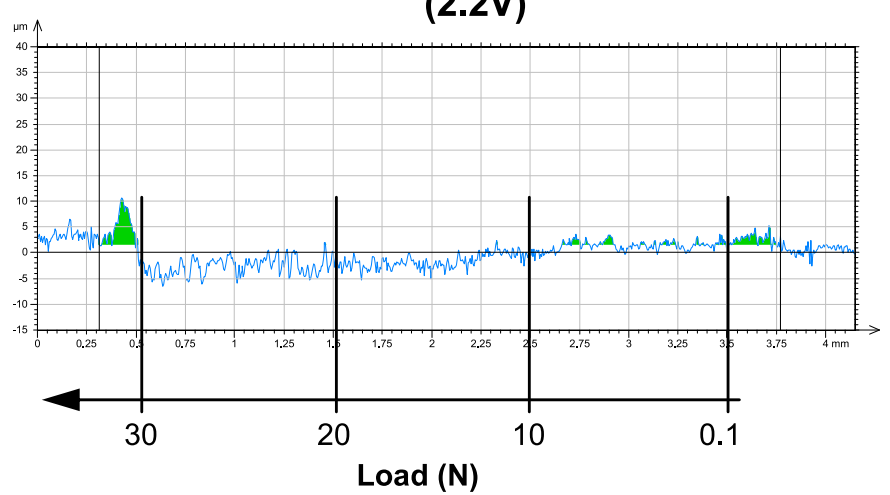

Fig. 10. Cross section profiles of the abrasion scars.

increases. Anodization increases surface roughness and produces an abrasion scar which depth still shows some proportionality to the applied load.

After treatment with [ImPhosphonate] at $1 \mathrm{~V}$, no real wear scar is observed, and the surface damage is negligible under the whole range of applied load.

The coating fails since the start of the sliding, at very low applied loads, for Anodized Al7075+[ImPhosphonate] (2 V), and particularly for Anodized Al7075+[ImPhosphate] (4 V), which presents severe wear along the whole scar.

The coating obtained for Anodized Al7075+[ImPhosphate] at $2.2 \mathrm{~V}$ shows the existence of a critical applied load of $8 \mathrm{~N}$ from which the penetration depth increase begins.

These results show the best performance of the phosphonate species with respect to the phosphate one, and the necessity of applying potentials within the passivation zone $(1 \mathrm{~V}$ for [ImPhosphonate] and
$2.2 \mathrm{~V}$ for [ImPhosphate]) in order to avoid dissolution and high reactivity.

The inclusion of IL anions in the anodized layer to form $\left[\mathrm{Al}_{2} \mathrm{O}_{3-\mathrm{x}}(\text { Anion })_{\mathrm{x}}\right]$ species has been previously described [2]. A similar mechanism could have taken place in the present case.

The different performance obtained for each IL could be related to the different anions and the different acidity of their water solutions. The low $\mathrm{pH}$ of the phosphate IL water solution would induce the dissolution of the anodized layer, while the modification of the alumina layer by the phosphonate IL would produce a more resistant layer.

\subsection{Cross section of the modified alumina layer}

In order to study the modification of the alumina layer due to the electrochemical treatment with the [ImPhosphonate] at $1 \mathrm{~V}$, we have performed a cross section of this sample. Fig. 11 shows the SEM 


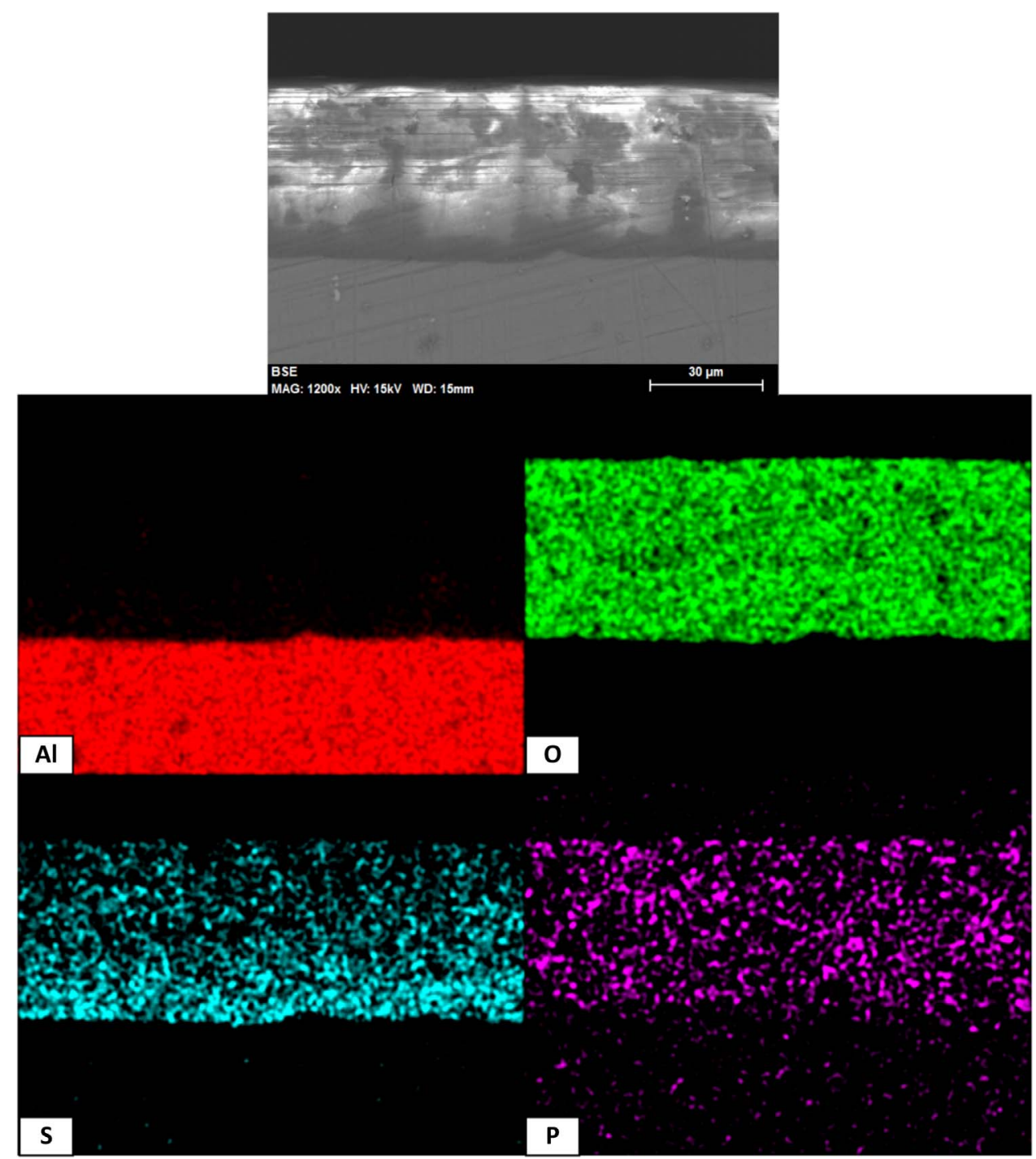

Fig. 11. SEM micrograph and elemental maps of cross section of Anodizing $+[$ ImPhosphonate $](1 \mathrm{~V})$ sample.

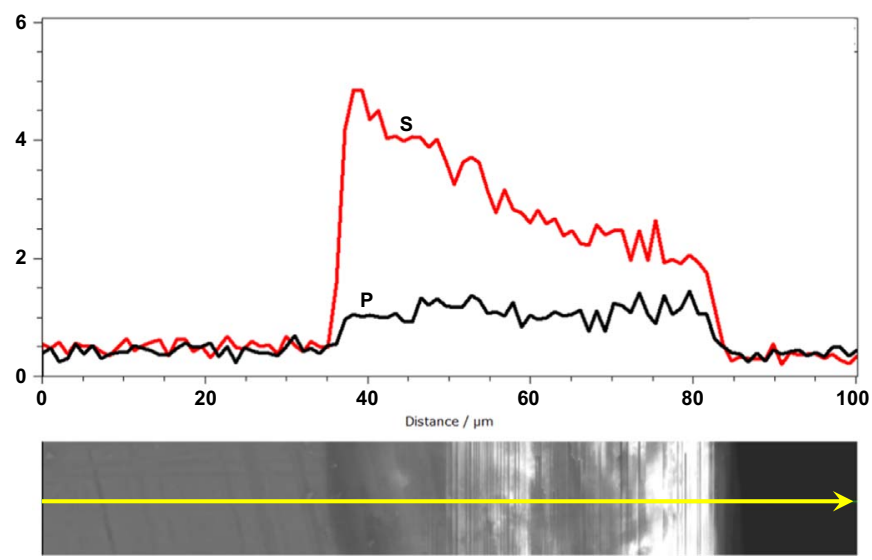

Fig. 12. Linear EDX Analysis of $P$ and $S$. Cross section of Anodizing +[ImPhosphonate] (1 V) sample.

micrograph of the cross section, where it can be observed that the thickness of the alumina layer is $40 \mu \mathrm{m}$, approximately. The elemental $\mathrm{Al}, \mathrm{O}, \mathrm{P}$ and $\mathrm{S}$ maps are also presented. It can be observed that $\mathrm{P}$ is homogeneously distributed in the whole thickness of the alumina layer, confirming that the IL-modified film is grown into the oxide layer. The linear EDX analysis of the sample (Fig. 12), from the aluminium alloy substrate to the surface, confirms that $\mathrm{P}$ content is constant in the whole alumina layer, while $\mathrm{S}$ is higher near the aluminium substrate, decreasing across the coating. These results confirm that the tribological enhancement of the described treatment is due to the modification of the alumina layer.

\section{Conclusions}

The surface layer on anodized Al7075 T6 has been modified by electrochemical treatment in aqueous solutions of phosphonate and phosphate imidazolium ionic liquids.

Surface analysis and electrochemical studies confirm the modification of the coating film under the mild conditions used.

The resulting surface coatings are modified by the presence of the IL anions, and show increased abrasion resistance under scratching with respect to the anodized alloy, only when the applied voltages lay within the corresponding passivation regions. Applied voltages below or above those regions reduce the abrasion resistance of the coatings.

The results presented here open up a new tribological application of ionic liquids, beyond their use as lubricants or lubricant additives. 


\section{Acknowledgments}

This work received the financial support of the Ministerio de Economía y Competitividad (MINECO, Spain) and the EU FEDER Program (Grant MAT2014-55384-P), and the Fundación Séneca, Agencia de Ciencia y Tecnología de la Región de Murcia for a "Ayuda a las Unidades y Grupos de Excelencia Científica de la Región de Murcia (Programa Séneca 2014)” (Grant 19877/GERM/14).

\section{References}

[1] K. Tateishi, A. Waki, H. Ogino, T. Ohishi, M. Murakami, Formation of $\mathrm{Al}_{2} \mathrm{O}_{3}$ film and $\mathrm{AlF}_{3}$ containing $\mathrm{Al}_{2} \mathrm{O}_{3}$ film by an anodic Polarization of aluminum in ionic liquids, Electrochemistry 80 (2012) 556-560.

[2] K. Tateishi, H. Ogino, A. Waki, T. Ohishi, M. Murakami, H. Asoh, S. Ono, Anodization behavior of aluminum in ionic liquids with a small amount of water, Electrochemistry 81 (2013) 440-447.

[3] M. Salerno, N. Patra, R. Losso, R. Cingolani, Increased growth rate of anodic porous alumina by use of ionic liquid as electrolyte additive, Mater Lett 63 (2009) 1826-1829.

[4] J.L. Goldman, A.B. McEwen, EMIIm and EMIBeti on aluminum anodic stability dependence on lithium salt and propylene carbonate, Electrochem Solid-State Lett 2 (1999) 501-503.
[5] B. Garcia, M. Armand, Aluminium corrosion in room temperature molten salt, J Power Sources 132 (2004) 206-208.

[6] C.X. Peng, L. Yang, Z. Zhang, K. Tachibana, Y. Yang, S. Zhao, Investigation of the anodic behavior of $\mathrm{Al}$ current collector in room temperature ionic liquid electrolytes, Electro Acta 53 (2008) 4764-4772.

[7] T. Espinosa, A.E. Jiménez, G. Martínez-Nicolás, J. Sanes, M.D. Bermúdez, Abrasion resistance of magnesium alloys with surface films generated from phosphonate imidazolium ionic liquids, Appl Surf Sci 320 (2014) 267-273.

[8] A.E. Jiménez, A. Rossi, M. Fantauzzi, T. Espinosa, J. Arias-Pardilla, G. MartínezNicolás, M.D. M.D.Bermúdez, Surface coating from phosphonate ionic liquid electrolyte for the enhancement of the tribological performance of magnesium alloy, ACS Appl Mater Interfaces 7 (2015) 10337-10347.

[9] P. Huang, J.A. Latham, D.R. MacFarlane, P.C. Howlett, M. Forsyth, A review of ionic liquid surface film formation on $\mathrm{Mg}$ and its alloys for improved corrosion performance, Electro Acta 110 (2013) 501-510.

[10] M.D. Bermúdez, A.E. Jiménez, G. Martínez-Nicolás, Study of surface interactions of ionic liquids with aluminium alloys in corrosion and erosion-corrosion processes, Appl Surf Sci 253 (2007) 7295-7302.

[11] P. Huang, P.C. Howlett, M. Forsyth, Electrochemical etching of AA5083 aluminium alloy in trihexyl(tetradecyl)phosphonium bis(trifluoromethylsulfonyl)amide ionic liquid, Corros Sci 80 (2014) 120-127.

[12] Arres MM, Jimenez AE, Arias-Pardilla J, Martinez-Nicolas G, Bermudez MD. Study of the effect of ionic liquid on the abrasion resistance of anodized aluminium alloys. 43rd Leeds-Lyon Symposium on Tribology, paper 25.2

[13] NIST X-ray Photoelectron Spectroscopy Databasehttp://srdata.nist.gov/xps/ (last accessed 07/01/2016). 